\title{
Effects of Hydrogen Plasma on the Electrical Properties of F-Doped ZnO Thin Films and p-i-n $\alpha$-Si:H Thin Film Solar Cells
}

\author{
Fang-Hsing Wang, ${ }^{1}$ Shang-Chao Hung, ${ }^{2}$ Cheng-Fu Yang, ${ }^{3}$ and Yen-Hsien Lee ${ }^{1}$ \\ ${ }^{1}$ Department of Electrical Engineering and Graduate Institute of Optoelectronic Engineering, National Chung Hsing University, \\ Taichung 40227, Taiwan \\ ${ }^{2}$ Department of Electrical Information Technology and Communications, Shih Chien University, Kaohsiung Campus, \\ Kaohsiung 84550, Taiwan \\ ${ }^{3}$ Department of Chemical and Materials Engineering, National University of Kaohsiung, Kaohsiung 81147, Taiwan
}

Correspondence should be addressed to Cheng-Fu Yang; cfyang@nuk.edu.tw

Received 10 March 2014; Accepted 11 April 2014; Published 4 May 2014

Academic Editor: Yen-Lin Chen

Copyright (C) 2014 Fang-Hsing Wang et al. This is an open access article distributed under the Creative Commons Attribution License, which permits unrestricted use, distribution, and reproduction in any medium, provided the original work is properly cited.

\begin{abstract}
$1.5 \mathrm{wt} \%$ zinc fluoride $\left(\mathrm{ZnF}_{2}\right)$ was mixed with zinc oxide powder to form the F-doped $\mathrm{ZnO}$ (FZO) composition. At first, the FZO thin films were deposited at room temperature and $5 \times 10^{-3}$ Torr in pure Ar under different deposition power. Hall measurements of the as-deposited FZO thin films were investigated, and then the electrical properties were used to find the deposition power causing the FZO thin films with minimum resistance. The FZO thin films with minimum resistance were further treated by $\mathrm{H}_{2}$ plasma and then found their variations in the electrical properties by Hall measurements. Hydrochloric $(\mathrm{HCl})$ acid solutions with different concentrations $(0.1 \%, 0.2 \%$, and $0.5 \%)$ were used to etch the surfaces of the FZO thin films. Finally, the as-deposited, HCletched as-deposited, and $\mathrm{HCl}$-etched $\mathrm{H}_{2}$-plasma-treated $\mathrm{FZO}$ thin films were used as transparent electrodes to fabricate the p-i-n $\alpha$-Si:H thin film solar cells and their characteristics were compared in this study. We would show that using $\mathrm{H}_{2}$-plasma-treated and $\mathrm{HCl}$-etched FZO thin films as transparent electrodes would improve the efficiency of the fabricated thin film solar cells.
\end{abstract}

\section{Introduction}

$\mathrm{ZnO}$ is a nontoxic, abundant, and inexpensive material; in addition, impurity-doped $\mathrm{ZnO}$ can have electrical and optical properties comparable to the expensive indium tin oxide (ITO) currently used commercially. For that, impuritydoped $\mathrm{ZnO}$ is a possible candidate for transparent conducting oxides (TCOs) for potential applications as a transparent electrode in flat panel displays (FPDs) and photovoltaic solar cells [1]. TCO thin films have been widely used in the applications of solar cells, flat panel displays, and more optoelectronic products. TCO thin films show a good combination of electrical conductivity at ambient temperature and optical transparency in a visible region [2]. Some especially interesting properties of $\mathrm{ZnO}$-based thin films are their low cost, ready availability, and high chemical stability. $\mathrm{ZnO}$ is a II-VI n-type semiconductor with a wide band gap of approximately $3.3 \mathrm{eV}$ at room temperature. Group III donor elements, such as B [3], $\mathrm{Al}$ [4], and $\mathrm{Ga}$ [5], are added to improve the electrical properties of $\mathrm{ZnO}$ thin films. Fluorine, the ionic radius $(0.136 \mathrm{~nm})$ of which is similar to that of oxygen $(0.132 \mathrm{~nm})$, may be an adequate anion doping candidate due to lower lattice distortion compared with $\mathrm{Al}$, $\mathrm{Ga}$, and In, but comparatively few studies on fluorine-doped $\mathrm{ZnO}$ (F-doped $\mathrm{ZnO}$ ) can be found in the past researches $[6,7]$.

In this study, $1.5 \mathrm{wt} \%$ zinc fluoride $\left(\mathrm{ZnF}_{2}\right)$ was mixed with zinc oxide powder to fabricate the F-doped $\mathrm{ZnO}$ (FZO) ceramic target for sputtering process [8]. In the past, Aldoped $\mathrm{ZnO}(\mathrm{AZO})$ thin films were deposited on glass substrate by RF magnetron sputtering by changing the substrate temperature from room temperature (RT) to $300^{\circ} \mathrm{C}[4]$. From this literature, we would know that hydrogen $\left(\mathrm{H}_{2}\right)$ has large effect on the $\mathrm{ZnO}$-based TCO thin films. When $\mathrm{H}_{2}$ was used as deposition atmosphere during the deposition process [4] or used as plasma treatment $[9,10]$ after the deposition process, the $\mathrm{ZnO}$-based TCO thin films will enhance their carrier concentration and improve their resistivity. In the 
past, we also found that the $\mathrm{H}_{2}$-plasma treatment on the deposited AZO thin films has large influence on their physical (transparency ratio and grain size) and electrical (energy gap and resistivity) properties [11]. For that, the plasma enhanced chemical vapor deposition (PECVD) $\mathrm{H}_{2}$ was treated on the as-deposited FZO thin films (abbreviated as plasma-treated FZO thin films). The effects of $\mathrm{H}_{2}$ plasma on the properties of FZO thin films were compared by observing the carrier concentration, carrier mobility, and resistivity. The FZO thin films under differently treated parameters were also used as the transparent electrodes of the $\alpha$-Si thin film solar cells. The current-voltage characteristics of the fabricated $\alpha$-Si thin film solar cells were measured to determine the effects of treated parameters of the FZO thin films on the characteristics of the fabricated $\alpha$-Si solar cells.

\section{Experimental}

$1.5 \mathrm{wt} \%$ zinc fluoride $\left(\mathrm{ZnF}_{2}\right)(99.995 \%)$ was mixed with zinc oxide powder (99.999\%) to form the F-doped $\mathrm{ZnO}$ (abbreviated as FZO) composition. After being dried and ground, the FZO powder was calcined at $600^{\circ} \mathrm{C}$ for $1 \mathrm{~h}$, then ground again, and mixed with polyvinyl alcohol (PVA) as binder. The mixed powders were uniaxially pressed into pellets of $5 \mathrm{~mm}$ thickness and $54 \mathrm{~mm}$ diameter using a steel die. After debindering, the $\mathrm{FZO}$ pellet was sintered at $1060^{\circ} \mathrm{C}$ for $3 \mathrm{~h}$. Glass substrates (Corning 1737) with an area of $3.3 \times 3.3 \mathrm{~cm}^{2}$ were cleaned ultrasonically with isopropyl alcohol (IPA) and deionized (DI) water and then dried under a blown nitrogen gas. The base pressure of the sputtering chamber was below $5 \times 10^{-6}$ Torr and the working pressure was maintained at $5 \times 10^{-3}$ Torr in pure Ar (99.995\%) ambient (abbreviated as-deposited FZO thin films). FZO thin films with a thickness of about $650 \mathrm{~nm} \pm 10 \%$ were deposited by RF magnetron sputtering on glass substrates at room temperature (RT) by controlling deposition time to find the deposition parameters at which FZO thin films had optimally electrical characteristics. At the first, the FZO thin films were deposited by changing RF power from $50 \mathrm{~W}$ to $150 \mathrm{~W}$ at RT. Thicknesses of the FZO thin films were measured using a SEMF-10 ellipsometer and confirmed by field emission scanning electron microscopy (FESEM). The crystalline structure of the FZO thin films was identified by X-ray diffraction (XRD), while the thin films' Hall-effect coefficients were determined by a Bio-Rad Hall set-up. The optical transmission spectrum was recorded using a Hitachi U-3300 UV-Vis spectrophotometer in the 300-800 nm wavelength range. The as-deposited FZO thin films with optimally electrical characteristics were treated by the plasma enhanced chemical vapor deposition (PECVD) hydrogen $\left(\mathrm{H}_{2}\right)$ (abbreviated as plasma-treated FZO thin films). The working pressure was maintained at 1 Torr under the $300 \mathrm{sccm} \mathrm{H}_{2}$ flow rate. The plasma power was changed from $0 \mathrm{~W}$ (without $\mathrm{H}_{2}$ plasma treatment) to $100 \mathrm{~W}$, and the plasma-treated temperature and time were $200^{\circ} \mathrm{C}$ and $60 \mathrm{~min}$.

After that, the thicknesses of the as-deposited and plasma-treated FZO thin films were extended to $1000 \mathrm{~nm}$ $\pm 10 \%$, and then their surfaces were etched by wet etching performed in diluted $\mathrm{HCl}$ solution with concentrations of $0.1 \%, 0.2 \%$, and $0.5 \%$ in $\mathrm{H}_{2} \mathrm{O}$ to acquire the textured $\mathrm{FZO}$ thin films. The thickness of the etched FZO thin films was around $650 \mathrm{~nm}$, which was obtained by controlling the etched time. Also, the surface texture of the etched FZO thin films was observed by FESEM. The etched as-deposited and plasmatreated FZO thin films were used as substrates to fabricate the superstrate $\mathrm{p}-\mathrm{i}-\mathrm{n} \alpha$-Si:H thin film solar cells. Thin film solar cells were fabricated using a single-chamber plasmaenhanced chemical vapor deposition unit at $200^{\circ} \mathrm{C}$, with a working pressure of $700 \times 10^{-3}$ Torr and a deposition power of $20 \mathrm{~W}$. The p-type $\alpha$-Si thin films (thickness was about $20 \mathrm{~nm}$ ) were deposited by controlling the gas flowing rates for $\mathrm{H}_{2}=100 \mathrm{sccm}, \mathrm{SiH}_{4}=20 \mathrm{sccm}, \mathrm{CH}_{4}=10 \mathrm{sccm}$, and $\mathrm{B}_{2} \mathrm{H}_{6}=$ $40 \mathrm{sccm}$. The i-type $\alpha$-Si thin films $(400 \mathrm{~nm})$ were deposited by using $\mathrm{H}_{2}=100 \mathrm{sccm}$ and $\mathrm{SiH}_{4}=10 \mathrm{sccm}$, and the p-type $\alpha$ $\mathrm{Si}(50 \mathrm{~nm})$ thin films were deposited by using $\mathrm{H}_{2}=100 \mathrm{sccm}$, $\mathrm{SiH}_{4}=20 \mathrm{sccm}$, and $\mathrm{PH}_{3}=20 \mathrm{sccm}$, respectively. The current-voltage characteristic of the fabricated solar cells was measured under an illumination intensity of $300 \mathrm{~mW} / \mathrm{cm}^{2}$ and an AM $1.5 \mathrm{G}$ spectrum.

\section{Results and Discussion}

An increase in orientation during crystalline growth is possible according to the model of Van der Drift, which is often referred to as "survival of the fastest" model. Even the grain sizes are not really formed, this model is based on different growth rates of the crystal planes. At first, the thin films start growing in random crystal orientation at the initial layer, they grow fastest in the plane parallel to the substrate and then grow at the cost of the others [12]. This "survival of the fastest" model implies a related increase in crystal orientation, which is called figure of merit in a growth of thin films, but the model cannot explain an increase in grain sizes with increasing thin films' thickness [13]. Figure 1 shows that even different deposition powers were used, all FZO thin films exhibited a strong (002) peak at $2 \theta=34.24^{\circ}$ and a weak (004) peak, which indicate that the c-axis is predominantly oriented parallel to the substrate normal. The results in Figure 1 prove that the deposited FZO thin films have the figure of merit in $c$ axis orientation. The absence of additional peaks in the XRD patterns excludes the possibility of any extra phases and/or large-size precipitates in the FZO thin films. The diffraction intensity of the (002) peak increased as the deposition power increased from $50 \mathrm{~W}$ to $150 \mathrm{~W}$.

The results of the carrier mobility, carrier concentration, and resistivity shown Figure 2 indicate that the electrical properties of the FZO thin films were dependent on deposition power. When plasma molecules are deposited on a glass substrate, many defects result and inhibit electron movement. As different deposition powers are used during the deposition process, two factors are believed to cause an increase in the carrier mobility of the FZO thin films. First, higher deposition power provides more energy and thus enhances the motion of plasma molecules, which will improve the crystallization and grain size growth of the FZO thin films, and also the defects in the thin films will be decreased. Second, as deposition power is raised, the defects in the FZO thin films decrease, and that will cause the decrease in the inhibiting of the barriers electron transportation 


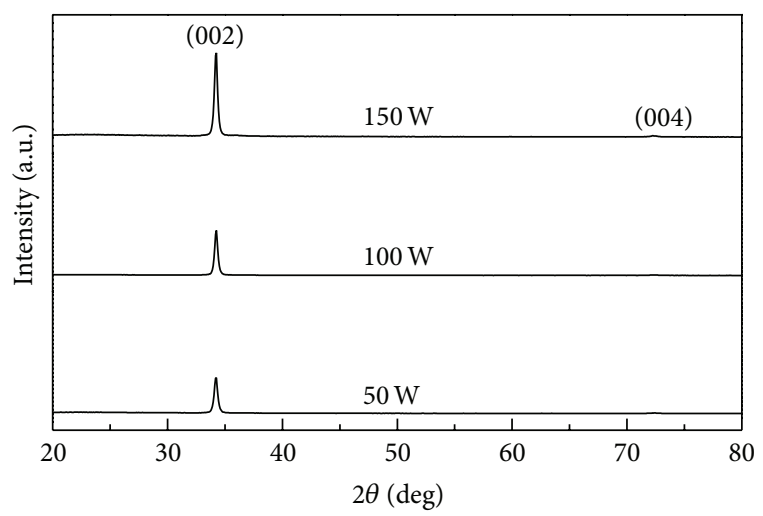

FIGURE 1: X-ray diffraction (XRD) patterns of the FZO thin films as a function of deposition power.

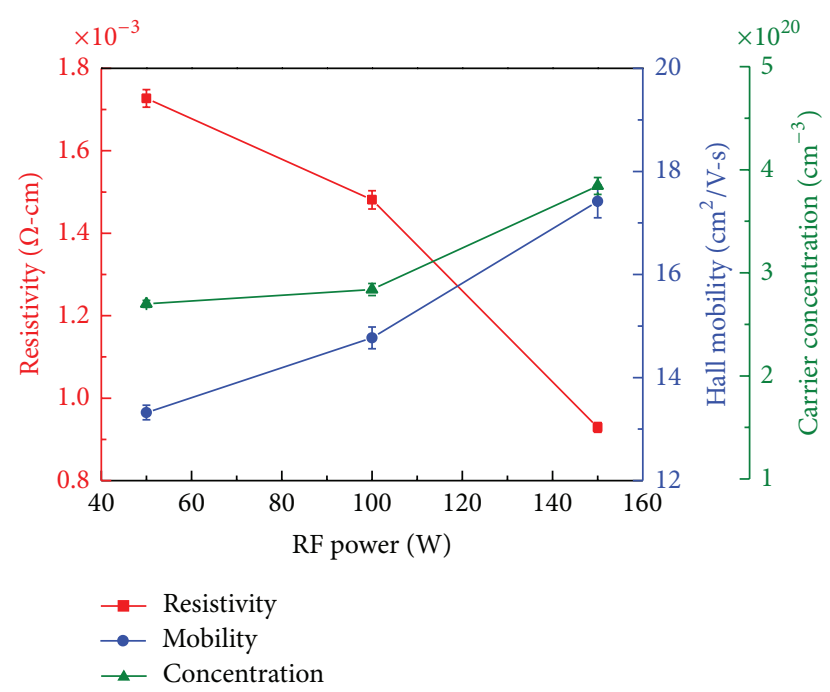

FIGURE 2: Carrier mobility, carrier concentration, and resistivity of the FZO thin films as a function of deposition power.

[14]. The results in Figure 1 suggest that this condition will dominate the characteristics of the deposited FZO thin films. As Figure 2 shows, both the carrier concentration and carrier mobility of the FZO thin films linearly increased with deposition power and reached the maximum concentration and carrier mobility at $150 \mathrm{~W}$. The resistivity of the TCO thin films is proportional to the reciprocal of the product of carrier concentration $N$ and mobility $\mu$ :

$$
\rho=\frac{1}{N e \mu} \text {. }
$$

Both the carrier concentration and the carrier mobility contribute to the conductivity. The resistivity decreased from $1.72 \times 10^{-3} \Omega$-cm to $9.29 \times 10^{-4} \Omega$-cm as the deposition power increased from $50 \mathrm{~W}$ to $150 \mathrm{~W}$. The minimum resistivity of the FZO thin films at deposition power of $150 \mathrm{~W}$ is mainly caused by the carrier concentration and mobility being at their maximum.

Because of the maximum mobility and carrier concentration and the minimum resistivity, the $150 \mathrm{~W}$-deposited FZO thin films are used for further treatment by $\mathrm{H}_{2}$ plasma.

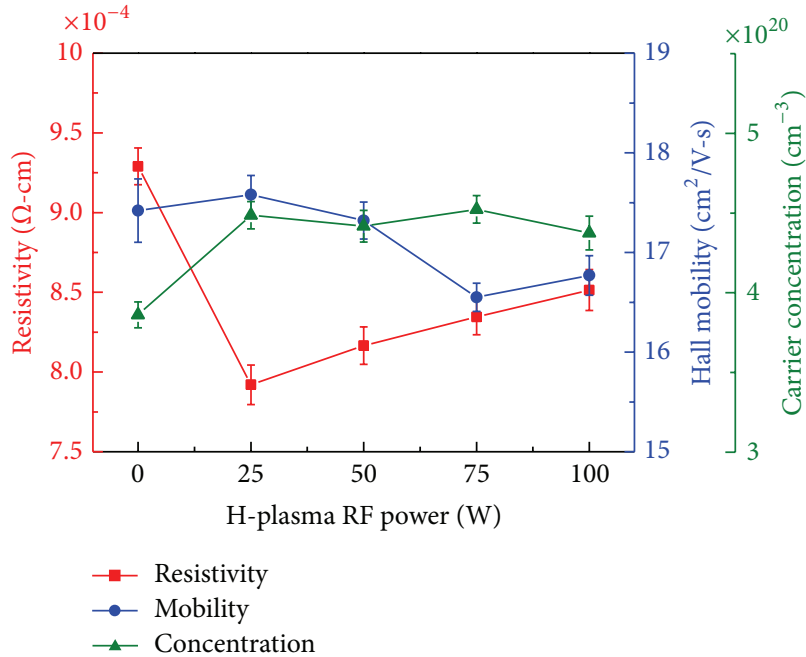

FIgURE 3: Carrier mobility, carrier concentration, and resistivity of the FZO thin films as a function of $\mathrm{H}_{2}$-plasma-treated power.

Figure 3 shows the carrier mobility, carrier concentration, and resistivity of the FZO thin films as a function of $\mathrm{H}_{2}$ plasma power. The mobility slightly increased as plasma power of $\mathrm{H}_{2}$ increased from $0 \mathrm{~W}$ (without $\mathrm{H}_{2}$ plasma treatment) to $25 \mathrm{~W}$ and then it decreased as plasma power was further increased. The carrier concentration first increased as plasma power of $\mathrm{H}_{2}$ increased from $0 \mathrm{~W}$ (without $\mathrm{H}_{2}$ plasma) to $25 \mathrm{~W}$ and then it reached a saturation value as plasma power was further increased. However, resistivity is really improved as plasma process is used because the carrier concentration is increased as $\mathrm{H}_{2}$ plasma is used. $25 \mathrm{~W}$-plasma-treated FZO thin films have the minimum resistivity of $7.92 \times 10^{-4} \Omega-\mathrm{cm}$ because the mobility and carrier concentration have their maximum. As the plasma power is higher than $25 \mathrm{~W}$, the mobility of the FZO thin films decreases because their surfaces are destroyed by $\mathrm{H}_{2}$ plasma.

Rough interfaces are usually introduced into solar cells by using substrates with textured surface [15]. It is well known that the front TCO thin films with textured surface can scatter more light at the $\mathrm{TCO} / \alpha-\mathrm{Si}: \mathrm{H}(\mathrm{p})$ interface and haze ratio is strongly influenced by the surface morphologies of TCO thin films or/and glass substrates. Therefore, the surface structures of glass substrate and TCO thin films play a vital role to improve the performance of thin film solar cells. A suitable textured surface is very important to increase the haze ratio and scatter an incident light, particularly the long wavelength light (red and near-infrared), to extend the effective path length within the active silicon layer and subsequent light trapping inside the absorber material of the solar cell [15]. In this study, diluted $\mathrm{HCl}$ etching of the as-deposited and plasma-treated FZO thin films has been carried out at room temperature to develop the textured surfaces for enhancing the efficiency of solar cells. FZO thin films deposited at $150 \mathrm{~W}$, room temperature, and $5 \times 10^{-3}$ Torr with thickness of $1000 \mathrm{~nm}$ were used as the etching samples. Figure 4 shows the etching rate of the FZO thin films as a function of concentration of $\mathrm{HCl}$ solution; the etched time was dependent on the concentration of $\mathrm{HCl}$ solution. As the 


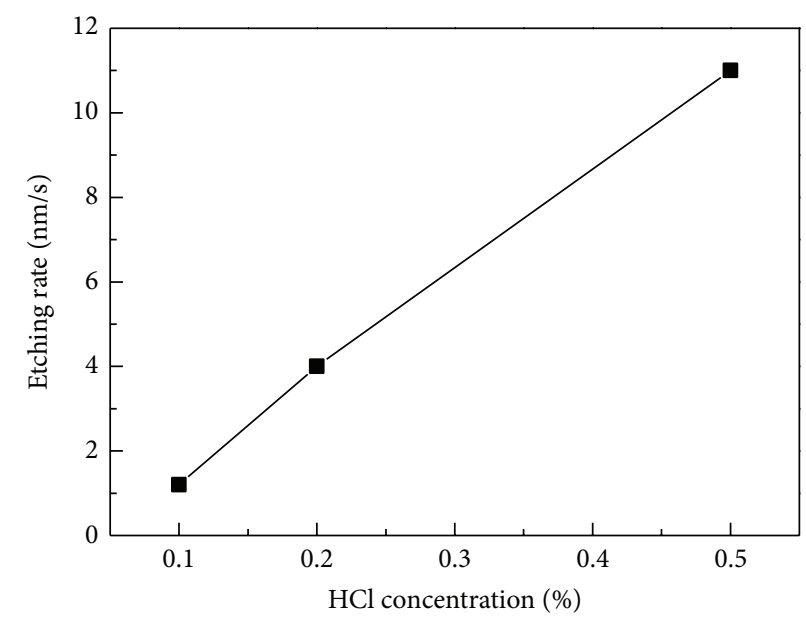

FIGURE 4: Etching rate of the FZO thin films as a function of $\mathrm{HCl}$ solution concentration.

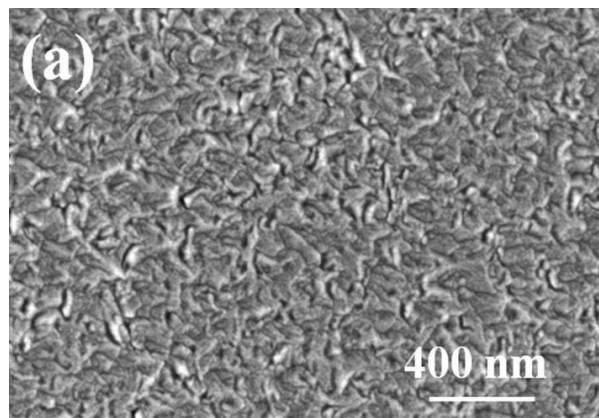

(a)

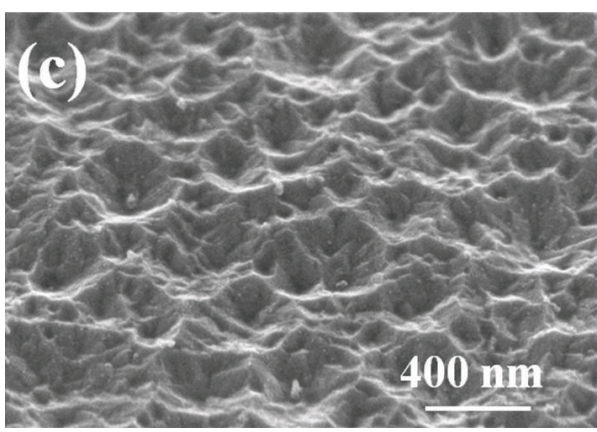

(c)

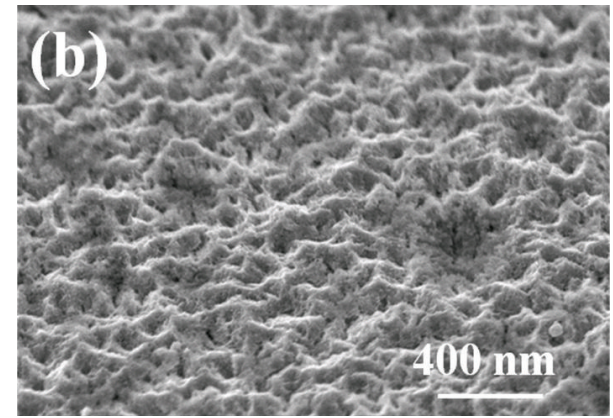

(b)

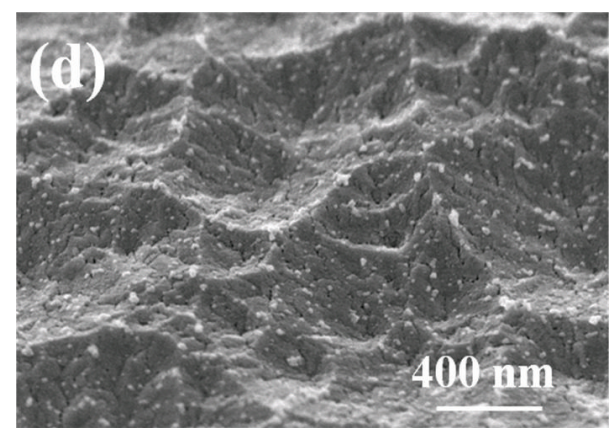

(d)

FIGURE 5: Surface morphology of the FZO thin films (a) as-deposited and etched at different $\mathrm{HCl}$ concentrations (b) $0.1 \%$, (c) $0.2 \%$, and (d) $0.5 \%$, respectively.

concentration of $\mathrm{HCl}$ solution increased from $0.1 \%$ to $0.5 \%$, the etched rate linearly increased from $1.2 \mathrm{~nm} / \mathrm{s}$ to $11 \mathrm{~nm} / \mathrm{s}$, and the thickness of the etched FZO thin films was controlled at around $650 \mathrm{~nm}$.

Figure 5 shows the surface morphology of the etched FZO thin films, and also the etched time was dependent on the concentration of $\mathrm{HCl}$ solution. Compared with the results shown in Figure 5, the surface roughness increased significantly after $\mathrm{HCl}$ etching. The etching process causes the thin films' surfaces to develop a crater-like cave and the size of cave increases with increasing $\mathrm{HCl}$ concentration. Figures 6(a) and 6(b) depict the total and diffused transmittance of the textured FZO thin films for various concentrations of
$\mathrm{HCl}$ solution. The average total transmittance of as-deposited FZO thin film substrates was $82.8 \%$, whereas the textured FZO thin films showed that the average total transmittance decreased with increasing concentration of $\mathrm{HCl}$ solution in the visible $(400 \sim 800 \mathrm{~nm})$ wavelength region. The average total transmittances of $81.1 \%, 79.2 \%$, and $78.8 \%$ were shown by the textured FZO thin films with various concentrations of $\mathrm{HCl}$ solution, including $0.1 \%, 0.2 \%$, and $0.5 \%$, respectively. In general, the diffused transmittance is related to the surface structure and roughness of the textured FZO thin films. The average diffused transmittance of the as-deposited FZO thin films was around $1.7 \%$, whereas it varied from $0.7 \%$ to $4.0 \%$ in the visible wavelength region. As the concentrations 


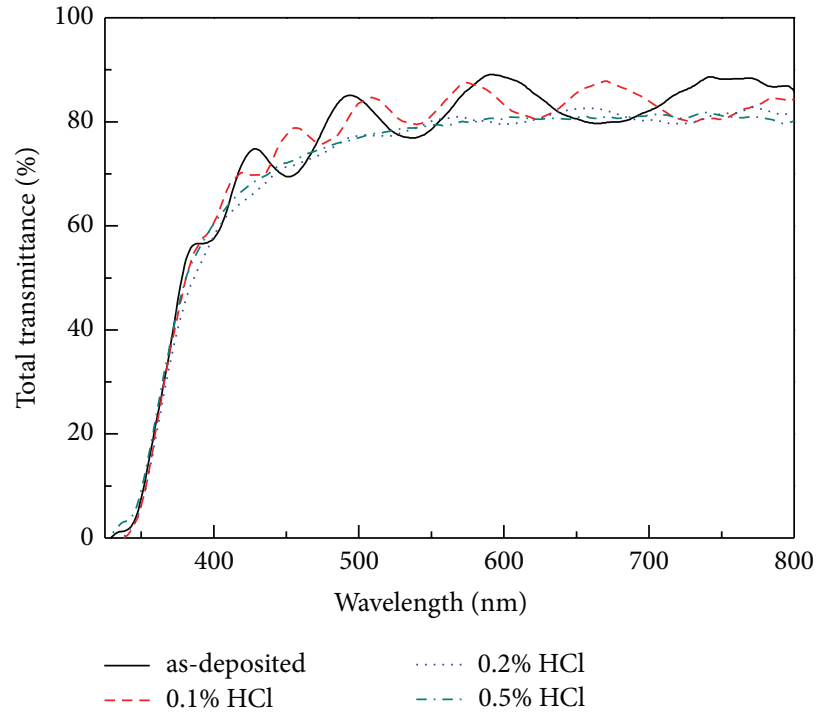

(a)

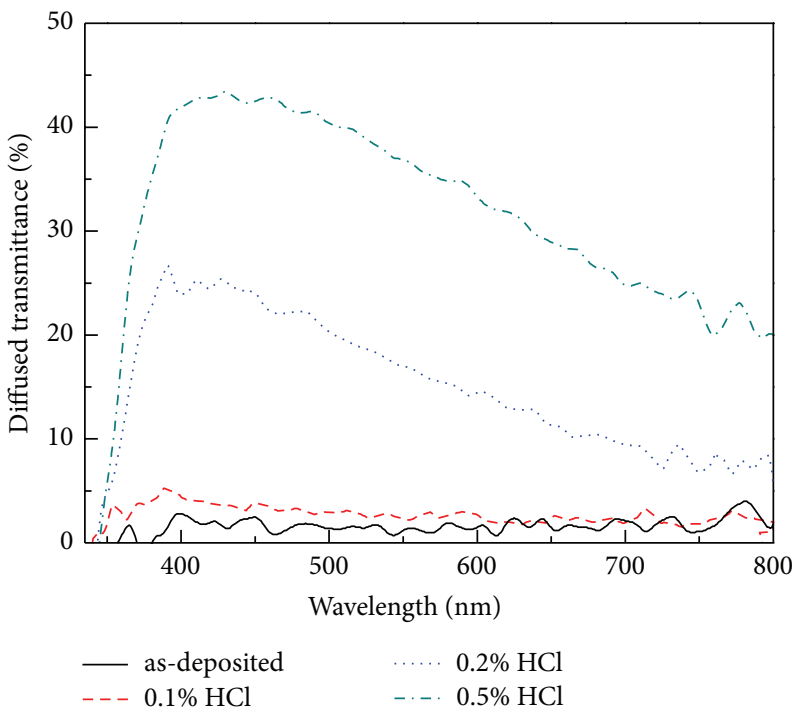

(b)

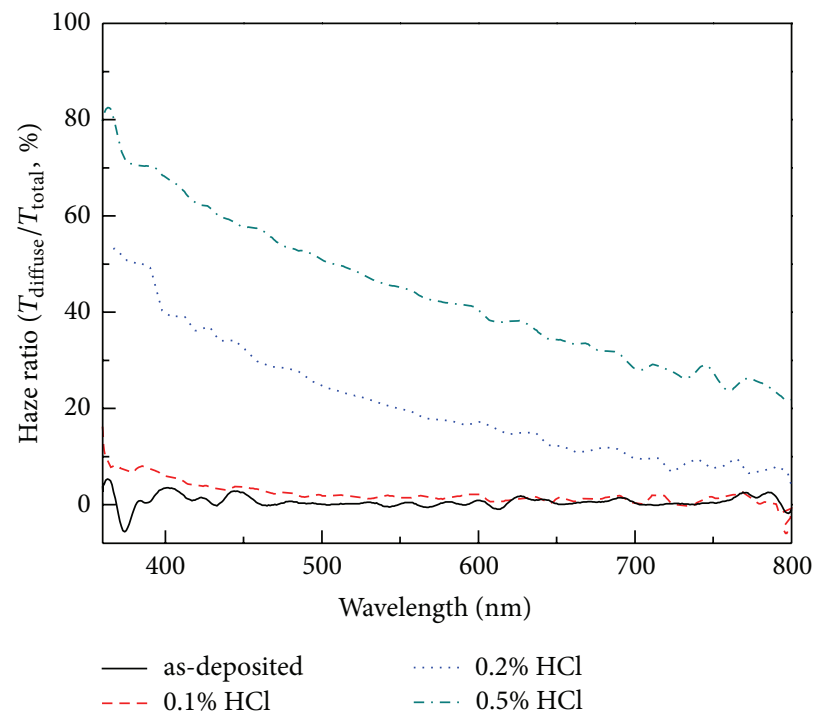

(c)

FIGURE 6: The optical characteristics: (a) total transmittance, (b) diffused transmittance, and (c) haze ratio of the HCl etched FZO substrates.

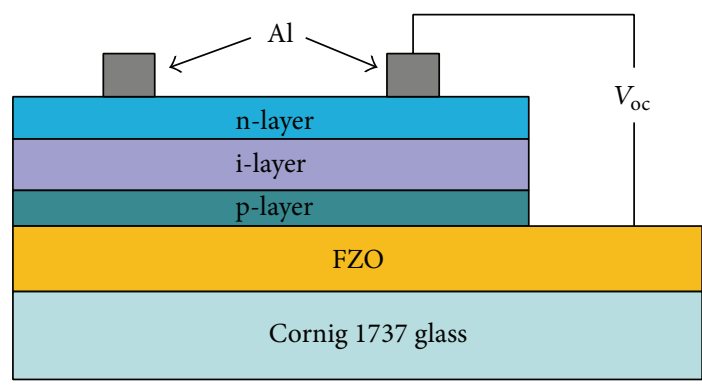

FIGURE 7: Structure configuration of the hydrogenated amorphous silicon thin film solar cells.

of $\mathrm{HCl}$ solution were $0.1 \mathrm{~mol} \%, 0.2 \mathrm{~mol} \%$, and $0.5 \%$, the average diffused transmittances were $2.6 \%, 15.0 \%$, and $32.8 \%$, whereas, in the visible wavelength region, they varied from
$1.3 \%$ to $4.1 \%$, from $1.3 \%$ to $25.3 \%$, and from $20.0 \%$ to $43.4 \%$, respectively. As the concentrations of $\mathrm{HCl}$ solution were $0.1 \mathrm{~mol} \%, 0.2 \mathrm{~mol} \%$, and $0.5 \%$, the maximum diffused transmittances were $5.4 \%$ (at $390 \mathrm{~nm}$ wavelength), $26.7 \%$ (at $390 \mathrm{~nm}$ wavelength), and $43.4 \%$ (at $430 \mathrm{~nm}$ wavelength), respectively. Figure $6(\mathrm{c})$ shows the haze ratio of the textured FZO thin films with various concentrations of $\mathrm{HCl}$ solution. The ratio of diffused to total transmittance is known as haze ratio. The average haze ratio of the textured FZO thin films in visible wavelength region was varied from $0.65 \%, 1.74 \%$, $18.4 \%$, and $41.2 \%$ as the $\mathrm{HCl}$ solution concentrations were $0.1 \mathrm{~mol} \%, 0.2 \mathrm{~mol} \%$, and $0.5 \%$, respectively.

A p-i-n structure is usually used for $\alpha$-Si thin film solar cells, as opposed to an n-i-p structure. This is because the mobility of electrons in $\alpha-\mathrm{Si}: \mathrm{H}$ is roughly 1 or 2 orders of magnitude larger than that of holes, and thus the collection 
TABLE 1: $V_{\text {oc }}$ value, $J_{\text {sc }}$ value, and F.F. value of the fabricated amorphous silicon thin film solar cells.

\begin{tabular}{|c|c|c|c|c|c|}
\hline FZO parameters & Abbreviated & $V_{\mathrm{oc}}(\mathrm{V})$ & $J_{\mathrm{sc}}\left(\mathrm{mA} / \mathrm{cm}^{2}\right)$ & F.F. & Efficiency (\%) \\
\hline as-deposited & A-FZO & 0.855 & 7.380 & 0.558 & 3.52 \\
\hline $0.2 \% \mathrm{HCl}$ & A2-FZO & 0.843 & 8.394 & 0.585 & 4.14 \\
\hline $0.5 \% \mathrm{HCl}$ & A5-FZO & 0.846 & 7.942 & 0.570 & 3.83 \\
\hline plasma treated & P-A-FZO & 0.854 & 7.692 & 0.552 & 3.63 \\
\hline $0.2 \% \mathrm{HCl}+$ plasma treated & P-A2-FZO & 0.840 & 8.764 & 0.578 & 4.26 \\
\hline $0.5 \% \mathrm{HCl}+$ plasma treated & P-A5-FZO & 0.850 & 8.109 & 0.574 & 3.95 \\
\hline
\end{tabular}

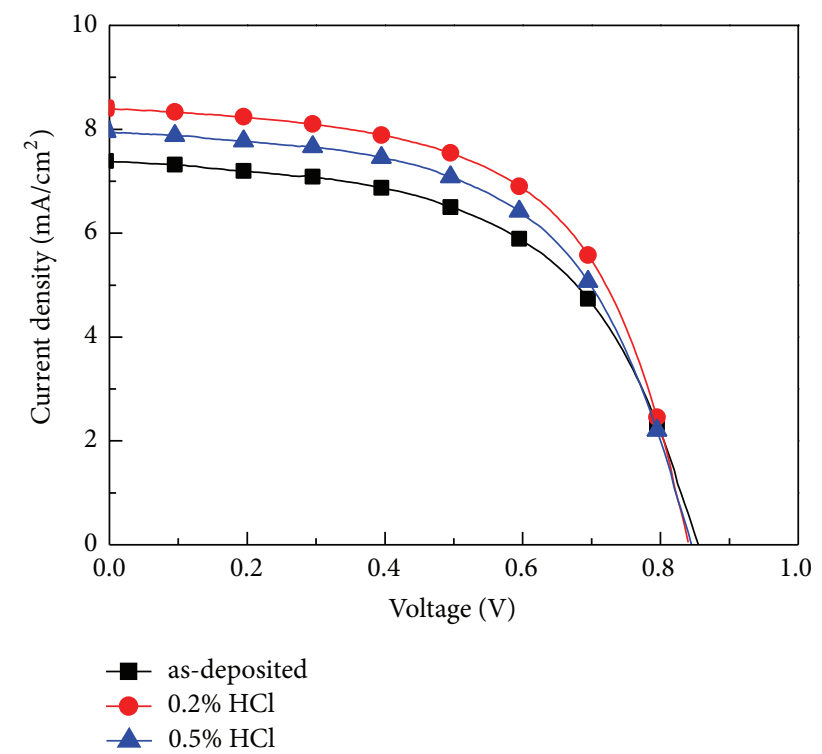

FIGURE 8: Current-voltage characteristics of the $\mathrm{p}-\mathrm{i}-\mathrm{n} \alpha-\mathrm{Si}: \mathrm{H}$ thin film solar cells under illumination.

rate of electrons moving from the $\mathrm{n}$ - to $\mathrm{p}$-type contact is better than holes moving from $\mathrm{p}$ - to n-type contact. For that, the superstrate $\mathrm{p}-\mathrm{i}-\mathrm{n}$ hydrogenated $\alpha$-Si thin film solar cells were fabricated using a single-chamber PECVD unit at $200^{\circ} \mathrm{C}$, and the structures of the designed solar cells are shown in Figure 7; no antireflective coatings were deposited on the cells. Although there are several reports related to the etching of glass substrates to improve the efficiency of the $\alpha$-Si thin film solar cells, texturing of patterned FZO thin films for high haze ratio in thin film solar cells is focused. At the first, as the as-deposited and etched as-deposited FZO thin films substrates are used, the values of open-circuit voltage $\left(V_{\text {oc }}\right)$, short-circuit current density $\left(J_{\text {sc }}\right)$, fill factor (F.F.), and efficiency $(\eta)$ are measured for the devices fabricated on those substrates.

Table 1 shows the measured current-voltage characteristics of the solar cells (substrate size $3.3 \times 3.3 \mathrm{~cm}^{2}$ ) under illumination as a function of differently treated processes. The abbreviated names of the FZO thin films under different processes are also shown in Table 1. Figure 8 shows that as the A-FZO, A2-FZO, and A5-FZO were used to fabricate the thin film silicon solar cells, the $V_{\mathrm{oc}}$ values of the solar cells were $0.855 \mathrm{~V}, 0.843 \mathrm{~V}$, and $0.846 \mathrm{~V}$; the $J_{\mathrm{sc}}$ values were $7.380 \mathrm{~mA} / \mathrm{cm}^{2}, 8.394 \mathrm{~mA} / \mathrm{cm}^{2}$, and $7.942 \mathrm{~mA} / \mathrm{cm}^{2}$; the F.F. values were $0.558,0.585$, and 0.570 ; and the efficiencies were

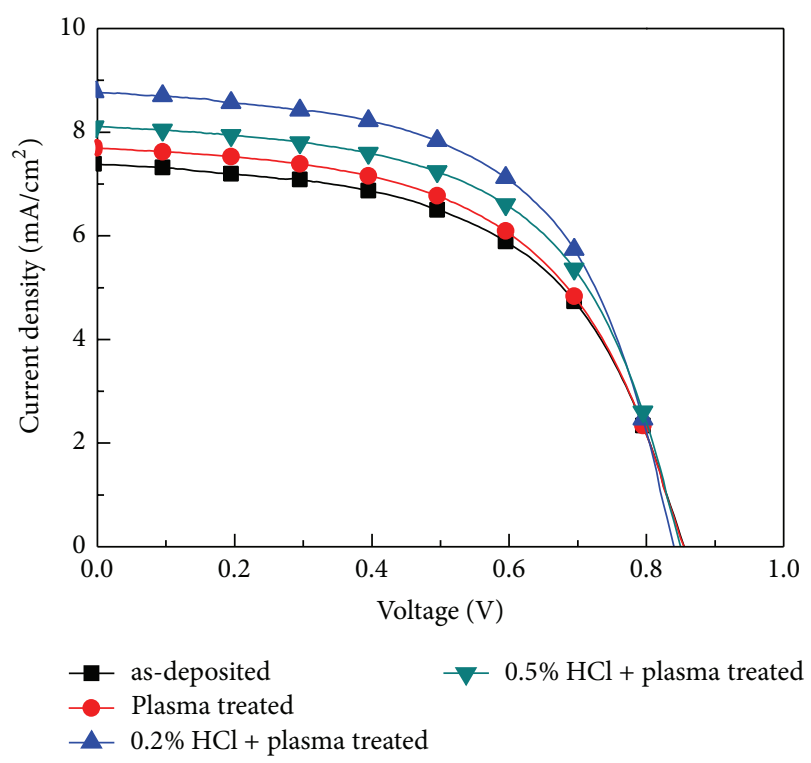

FIGURE 9: Current-voltage characteristics of the $\mathrm{p}-\mathrm{i}-\mathrm{n} \alpha$-Si:H thin film solar cells under illumination.

$3.52 \pm 0.17,4.14 \pm 0.13$, and $3.83 \pm 0.15$, respectively. Those results suggest that the surface texture (or the haze ratio) of the FZO thin films is the key parameter to improve the performance of the $\alpha$-Si:H thin film solar cells.

Figure 9 shows that as the P-A-FZO, P-A2-FZO, and PA2-FZO were used to fabricate the thin film silicon solar cells, the $V_{\text {oc }}$ values of the solar cells were $0.854 \mathrm{~V}, 0.840 \mathrm{~V}$, and $0.850 \mathrm{~V}$; the $J_{\mathrm{sc}}$ values were $7.692 \mathrm{~mA} / \mathrm{cm}^{2}, 8.764 \mathrm{~mA} / \mathrm{cm}^{2}$, and $8.109 \mathrm{~mA} / \mathrm{cm}^{2}$; the F.F. values were $0.552,0.578$, and 0.574 ; and the efficiencies were $3.63 \pm 0.15,4.26 \pm 0.11$, and $3.95 \pm 0.13$, respectively. As Figure 9 shows, the $V_{\mathrm{oc}}$ value and F.F. value had no changes, the $J_{\text {sc }}$ value increased, and the efficiency increased as the $\mathrm{H}_{2}$ plasma was used to treat the nonetched and etched FZO thin films. Those measured results of the fabricated $\alpha$-Si thin film solar cells are also compared in Table 1. The greater efficiencies in etched FZO substrates are mainly ascribable that as the haze ratio increases, the absorption of light increases, and then the short-circuit current density increases.

\section{Conclusions}

In this study, resistivity is really improved as $\mathrm{H}_{2}$-plasma process was used because the carrier concentration was increased 
and $25 \mathrm{~W}$ plasma-treated FZO thin films have the minimum resistivity of $7.92 \times 10^{-4} \Omega-\mathrm{cm}$. The average haze ratio of the etched as-deposited FZO thin films increased from $0.65 \%$ to $41.2 \%$ as the concentration of $\mathrm{HCl}$ solution increased from $0.0 \%$ (nonetched) to $0.5 \%$. As the as-deposited $\mathrm{FZO}$ thin films in the fabricated $\alpha-\mathrm{Si}: \mathrm{H}$ thin film solar cells were changed to the $0.2 \mathrm{HCl}$-etched FZO ones, the $J_{\text {sc }}$ values were improved from $7.380 \mathrm{~mA} / \mathrm{cm}^{2}$ to $8.394 \mathrm{~mA} / \mathrm{cm}^{2}$, the F.F. values were improved from 0.558 to 0.585 , and the efficiencies were improved from $3.52 \pm 0.17$ to $4.14 \pm 0.13$, respectively. When the $0.2 \mathrm{HCl}$-etched $\mathrm{H}_{2}$-plasma-treated FZO thin films were used as the electrodes, the fabricated solar cells had the optimal characteristics of $J_{\mathrm{sc}}$ value of $8.764 \mathrm{~mA} / \mathrm{cm}^{2}$, F.F. value of 0.578 , and efficiency of $4.26 \pm 0.11$, respectively. For the FZO thin films, the haze ratio increased with increasing concentration of $\mathrm{HCl}$ solution and the carrier concentration increased as $\mathrm{H}_{2}$ plasma was used. That would effectively enhance light trapping and increase the electrons inside the absorber material of solar cells and then improve the efficiency of the fabricated thin film solar cells.

\section{Conflict of Interests}

The authors declare that there is no conflict of interests regarding the publication of this paper.

\section{Acknowledgments}

The authors acknowledge financial supports of NSC 101-2221E-005-065, NSC 102-2622-E-390-002-CC3, and NSC 1022221-E-390-027.

\section{References}

[1] Ü. Özgür, Y. I. Alivov, C. Liu et al., "A comprehensive review of ZnO materials and devices," Journal of Applied Physics, vol. 98, no. 4, Article ID 041301, 103 pages, 2005.

[2] T. Minami, "Substitution of transparent conducting oxide thin films for indium tin oxide transparent electrode applications," Thin Solid Films, vol. 516, no. 7, pp. 1314-1321, 2008.

[3] B. N. Pawar, G. Cai, D. Ham et al., "Preparation of transparent and conducting boron-doped $\mathrm{ZnO}$ electrode for its application in dye-sensitized solar cells," Solar Energy Materials and Solar Cells, vol. 93, no. 4, pp. 524-527, 2009.

[4] C. C. Huang, F. H. Wang, and C. F. Yang, "Effects of deposition temperature and hydrogen flow rate on the properties of the Aldoped $\mathrm{ZnO}$ thin films and amorphous silicon thin-film solar cells," Applied Physics A, vol. 112, no. 4, pp. 877-883, 2013.

[5] F. H. Wang, C. C. Huang, C. F. Yang, and H. T. Tzeng, "Optical and electrical properties of the different magnetron sputter power $300^{\circ} \mathrm{C}$ deposited $\mathrm{Ga}_{2} \mathrm{O}_{3}-\mathrm{ZnO}$ thin films and applications in $\mathrm{p}-\mathrm{i}-\mathrm{n} \alpha$-Si:H thin-film solar cells," International Journal of Photoenergy, vol. 2013, Article ID 270389, 7 pages, 2013.

[6] L. Cao, L. Zhu, J. Jiang, R. Zhao, Z. Ye, and B. Zhao, "Highly transparent and conducting fluorine-doped $\mathrm{ZnO}$ thin films prepared by pulsed laser deposition," Solar Energy Materials and Solar Cells, vol. 95, no. 3, pp. 894-898, 2011.

[7] H. S. Yoon, K. S. Lee, T. S. Lee et al., "Properties of fluorine doped $\mathrm{ZnO}$ thin films deposited by magnetron sputtering,"
Solar Energy Materials and Solar Cells, vol. 92, no. 11, pp. 1366$1372,2008$.

[8] F. H. Wang, C. F. Yang, and Y. H. Lee, "Deposition of F-doped $\mathrm{ZnO}$ transparent thin films using $\mathrm{ZnF}_{2}$-doped $\mathrm{ZnO}$ target under different sputtering substrate temperatures," Nanoscale Research Letters, vol. 9, no. 1, article 97, 2014.

[9] R. Das, T. Jana, and S. Ray, "Degradation studies of transparent conducting oxide: a substrate for microcrystalline silicon thin film solar cells," Solar Energy Materials and Solar Cells, vol. 86, no. 2, pp. 207-216, 2005.

[10] N. Ohashi, Y. Wang, T. Ishigaki et al., "Lowered stimulated emission threshold of zinc oxide by hydrogen doping with pulsed argon-hydrogen plasma," Journal of Crystal Growth, vol. 306, no. 2, pp. 316-320, 2007.

[11] F. H. Wang, C. F. Yang, J. C. Liou, and I. C. Chen, "Effects of hydrogen on the optical and electrical characteristics of the sputter-deposited $\mathrm{Al}_{2} \mathrm{O}_{3}$-doped $\mathrm{ZnO}$ thin films," Journal of Nanomaterials, vol. 2014, Article ID 857614, 7 pages, 2014.

[12] F. C. M. van de Pol, F. R. Blom, and T. J. A. Popma, "R.F. planar magnetron sputtered $\mathrm{ZnO}$ films I: structural properties," Thin Solid Films, vol. 204, no. 2, pp. 349-364, 1991.

[13] A. van der Drift, "Evolutionary selection, a principle governing growth orientation in vapour-deposited layers," Philips Research Reports, vol. 22, pp. 267-288, 1967.

[14] Y. Igasaki and H. Saito, "Substrate temperature dependence ofelectrical properties of $\mathrm{ZnO}: \mathrm{Al}$ epitaxial films on sapphire (1210)," Journal of Applied Physics, vol. 69, no. 4, pp. 2190-2195, 1991.

[15] F. Wang, H. Chang, C. Tseng, C. Huang, and H. Liu, "Influence of hydrogen plasma treatment on $\mathrm{Al}$-doped $\mathrm{ZnO}$ thin films for amorphous silicon thin film solar cells," Current Applied Physics, vol. 11, supplement 1, pp. S12-S16, 2011. 

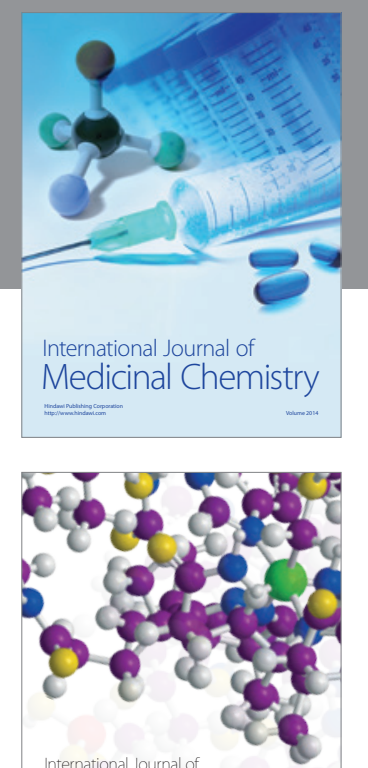

\section{Carbohydrate} Chemistry

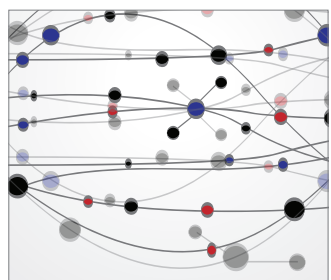

The Scientific World Journal
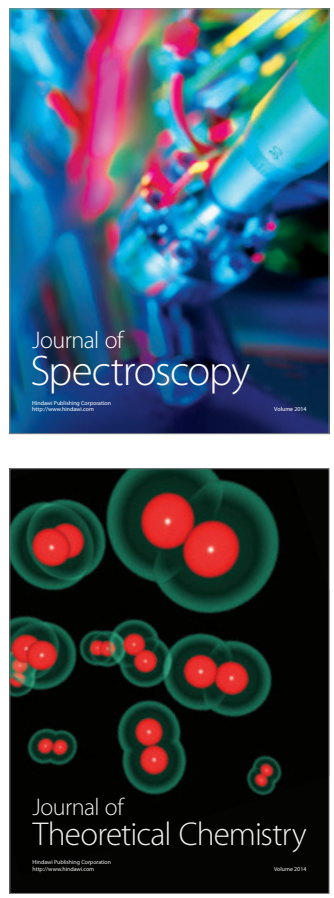
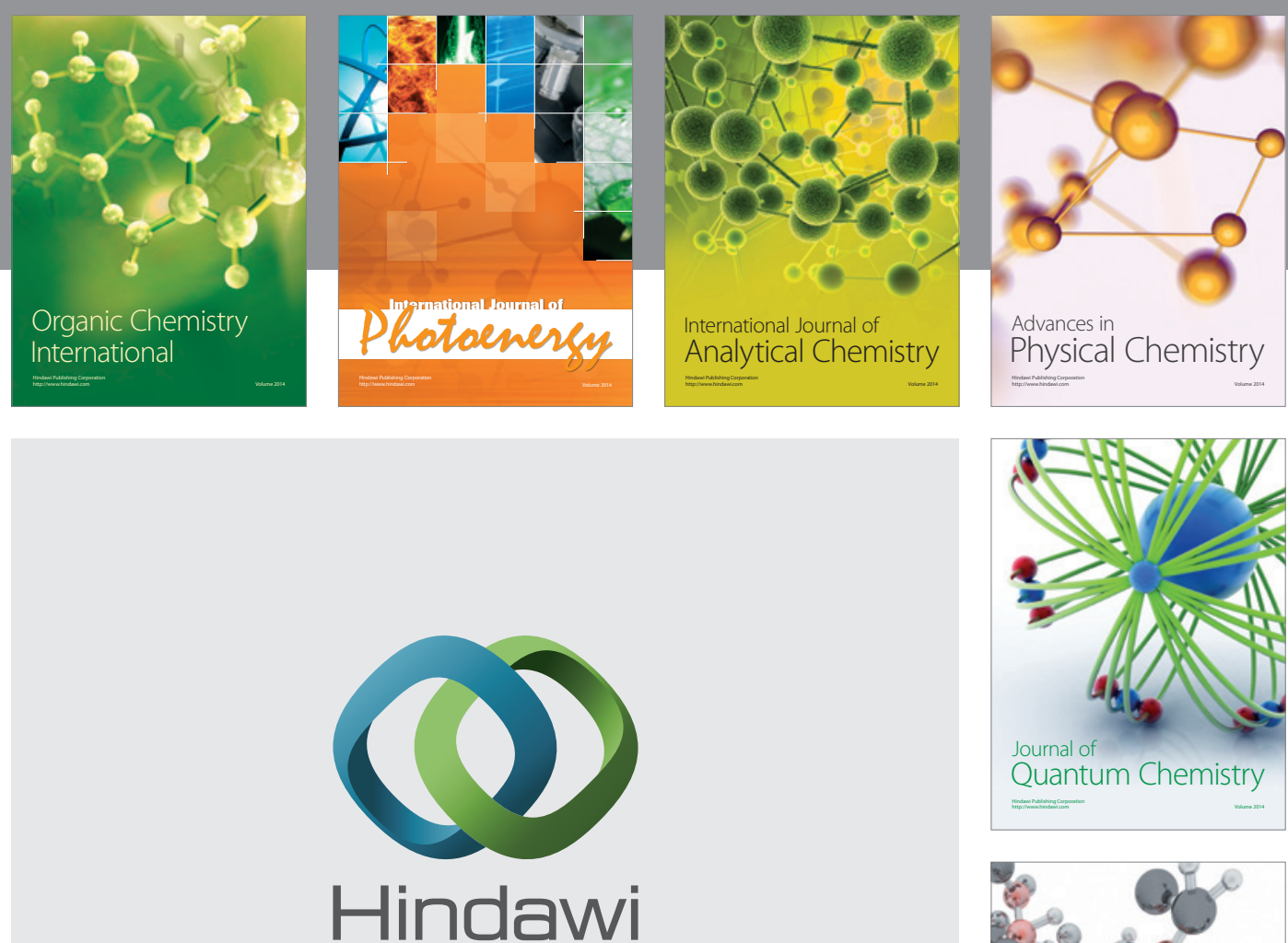

Submit your manuscripts at

http://www.hindawi.com

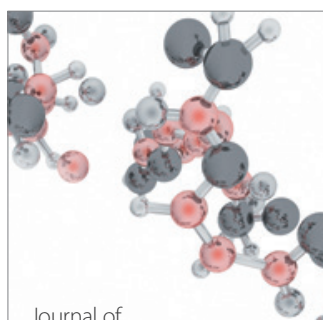

Analytical Methods

in Chemistry

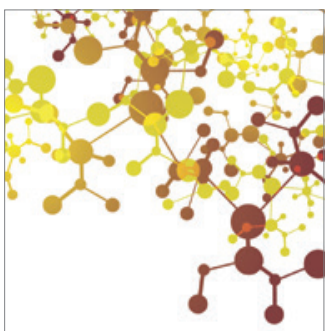

Journal of

Applied Chemistry

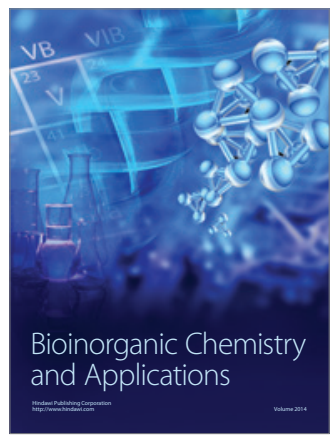

Inorganic Chemistry
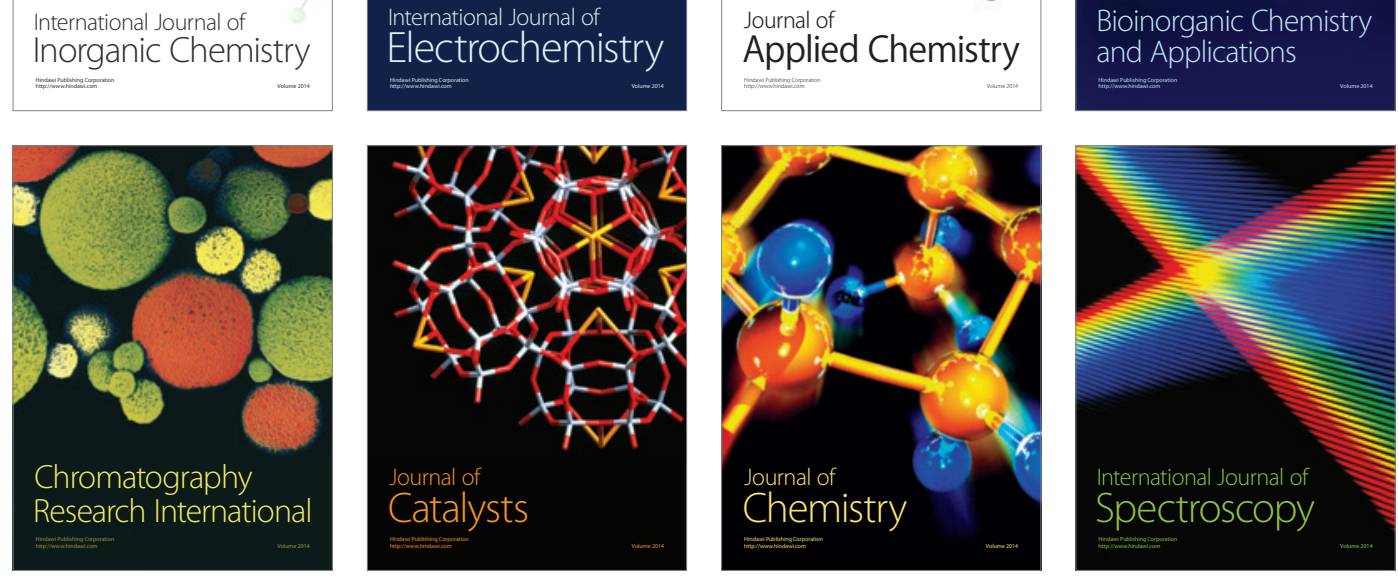